B. I. Freedman - S. S. Rich - M. M. Sale - G. Heiss • L. Djoussé - J. S. Pankow - M. A. Province - D. C. Rao • C. E. Lewis - Y. D. I. Chen - S. R. Beck - on behalf of the HyperGEN Investigators

\title{
Genome-wide scans for heritability of fasting serum insulin and glucose concentrations in hypertensive families
}

Received: 15 July 2004 / Accepted: 7 November 2004 / Published online: 4 March 2005

(C) Springer-Verlag 2005

\begin{abstract}
Aims/hypothesis: The heritability of fasting serum insulin and glucose concentrations in non-diabetic members of multiplex hypertensive families is unknown. Methods: We calculated the familial aggregation of fasting serum glucose and insulin concentrations and performed a genome-wide scan to assess whether quantitative trait loci contribute to these phenotypes in 2,412 non-diabetic individuals from 1,030 families enrolled in the Hypertension Genetic Epidemiology Network (HyperGEN) in the Family Blood Pressure Program. Results: The heritability $( \pm \mathrm{SE}$ ) of fasting serum insulin was $0.47 \pm 0.085$ in European Americans and $0.28 \pm 0.08$ in African Americans $(p<0.0001$ for both), after adjusting for age, sex, and BMI. A genomewide scan for fasting serum insulin yielded a maximum $\log$ of the odds (LOD) score of 2.36 on chromosome 5 at $20 \mathrm{cM}(p=0.0004)$ in European Americans, and an LOD score of 2.28 on chromosome 19 at $11 \mathrm{cM}(p=0.0004)$ in African Americans. The heritability of fasting serum glucose was $0.5109 \pm 0.08$ in the former and $0.29 \pm 0.09$ in the latter ( $p<0.0003$ for both) after adjusting for age, sex and
\end{abstract}

B. I. Freedman $(\bowtie) \cdot$ M. M. Sale

Department of Internal Medicine,

Sections on Nephrology and Endocrinology

The Wake Forest University School of Medicine,

Medical Center Boulevard,

Winston-Salem, NC, 27157-1053, USA

e-mail: bfreedma@wfubmc.edu

Tel.: +1-336-7166192

Fax: $+1-336-7164318$

S. S. Rich · S. R. Beck

Public Health Sciences

Wake Forest University School of Medicine,

Winston-Salem, NC, USA

M. M. Sale

Center for Human Genomics

Wake Forest University School of Medicine,

Winston-Salem, NC, USA

G. Heiss

Department of Epidemiology,

University of North Carolina,

Chapel Hill, NC, USA
BMI. A genome-wide scan for fasting serum glucose revealed a maximum LOD score of 2.07 on chromosome 5 at $26 \mathrm{cM}(p=0.0009)$ in European Americans. Conclusions/ interpretation: These analyses demonstrate the marked heritability of fasting serum insulin and glucose concentrations in families enriched for the presence of members with hypertension. They suggest that genes associated with fasting serum insulin concentration are present on chromosomes 19 and 5, and that genes associated with fasting serum glucose concentration are on chromosome 5 , in families enriched for hypertension.

Keywords African Americans - Essential hypertension Fasting blood sugar · Heritability · Linkage analysis . Serum insulin concentration

Abbreviations AA: African American - EA: European American - FBPP: Family Blood Pressure Program $\cdot h^{2}$ : heritability - HOMA: homeostasis model assessment . HyperGEN: Hypertension Genetic Epidemiology

\author{
L. Djoussé \\ Evans Department of Medicine, Section of Preventive \\ Medicine and Epidemiology, Boston University, \\ Boston, MA, USA \\ J. S. Pankow \\ Department of Epidemiology, \\ University of Minnesota, \\ Minneapolis, MN, USA \\ M. A. Province · D. C. Rao \\ Division of Biostatistics \\ Washington University School of Medicine, \\ St. Louis, MO, USA \\ C. E. Lewis \\ Department of Preventive Medicine, \\ University of Alabama, \\ Birmingham, AL, USA \\ Y. D. I. Chen \\ Department of Internal Medicine, \\ Cedars-Sinai Medical Center, \\ Los Angeles, CA, USA
}


Network - IBD: Identity-by-descent - LOD: Log of the odds - NHLBI: National Heart, Lung and Blood Institute · SOLAR: Sequential oligogenic linkage analysis routines

\section{Introduction}

Hyperinsulinaemia is a major risk factor for the subsequent development of type 2 diabetes mellitus [1,2]. Fasting serum insulin concentrations are excellent estimates of insulin resistance and the resulting hyperinsulinaemia in population studies, and have been shown to aggregate in families [3]. Insulin resistance is associated with increased serum triglyceride levels, reduced high-density lipoprotein concentrations and reduced low-density lipoprotein particle size; these metabolic parameters predict increased cardiovascular morbidity and mortality $[4,5]$.

The heritability $\left(h^{2}\right)$ and roles of inherited and environmental factors in causing hyperglycaemia and elevated serum insulin concentrations among hypertensive subjects remain unknown. In non-hypertensive populations, an adjusted $h^{2}$ value of 0.34 for fasting serum glucose [6] and 0.46 for fasting serum insulin concentrations [7] were reported in the Framingham Offspring Study. Similar high familial correlations for these prediabetic measures were reported in Amish families [8], the HERITAGE FAMILY study [9], and Caucasian twins [3]. Elevated serum insulin and glucose concentrations represent an increased risk of developing overt type 2 diabetes mellitus, with increased rates of cardiovascular morbidity and mortality [10].

It is likely that both genetic and environmental factors determine fasting serum insulin and glucose concentrations in hypertensive subjects. The Hypertension Genetic Epidemiology Network (HyperGEN) is a family-based consortium seeking to identify the genes responsible for elevated blood pressure [11]. We performed maximum likelihood variance component linkage analysis of fasting serum glucose and insulin concentrations and homeostasis model assessment (HOMA) to identify loci contributing to the variance of these traits in the non-diabetic relatives of families enriched for the presence of essential hypertension.

\section{Subjects and methods}

Population Participants in the HyperGEN Network of the Family Blood Pressure Program (FBPP), sponsored by the National Heart, Lung and Blood Institute (NHLBI), were evaluated. HyperGEN study methods have previously been reported [11]. In brief, family members were recruited from five clinical centers (Framingham, MA; Minneapolis, MN; Salt Lake City, UT; Forsyth County, NC; and Birmingham, AL). Participants provided written informed consent and the project was approved by the Institutional Review Boards at all of the institutions. A sibship was ascertained if it had two or more siblings with hypertension (defined as blood pressure $\geq 140 / 90$ or the use of anti-hypertensive medications), with an age at diagnosis of less than 60 years. Participants reporting a personal history of diabetes mellitus, having a fasting blood glucose concentration of $6.99 \mathrm{mmol} / \mathrm{l}$ or higher, or being treated with insulin or oral hypoglycaemic agents were excluded from analyses.

Phenotyping Morning fasting serum samples from study participants were collected in a resting state and run in duplicate for insulin concentration on an automated immunoassay instrument and its ultra-sensitive insulin kit (Beckman Coulter, Fullerton, CA, USA) [12]. The sensitivity of this assay is $0.03 \mathrm{mU} / 1(0.21 \mathrm{pmol} / \mathrm{l})$ and the dynamic range is $0.03-300 \mathrm{mU} / 1(0.21-2100 \mathrm{pmol} / \mathrm{l})$. There is zero crossreactivity with pro-insulin and $\mathrm{C}$-peptide, $30 \%$ with bovine insulin, and $97 \%$ with porcine insulin.

Serum glucose concentrations were measured using Elan Glucose reagent (hexokinase method) [13]. Assay sensitivity is $0.11-24.98 \mathrm{mmol} / \mathrm{l}$ and the detection limit $0.11 \mathrm{mmol} / 1$ is documented through the repetitive assay of a diluted serum control. The observed detection limit, calculated as two standard deviations of a 30-replicate within-run precision study, is $0.57 \mathrm{mmol} / \mathrm{l}$ and is below the claimed limit of $0.11 \mathrm{mmol} / \mathrm{l}$.

HOMA was calculated as (fasting serum insulin*fasting serum glucose)/22.5.

Genotyping Genotyping was performed by the NHLBIfunded Mammalian Genotyping Service. For additional information regarding the genotyping methods see the website of the Center for Medical Genetics at the Marshfield Medical Research Foundation http://www.research. marshfieldclinic.org/genetics/). The genome screen was performed by means of an automated technique with the scanning fluorescence detector. The Cooperative Human Linkage Center screening set 8, including 387 microsatellite markers spaced approximately every $9 \mathrm{cM}$ throughout the genome, was used, with an average marker heterozygosity of 0.76 .

Statistical analysis The distributions of fasting serum insulin and glucose concentrations were positively skewed. The natural logarithm transformed both insulin and glucose to approximate normality and was used for all analyses and model building. Any highly influential outliers were excluded from the analyses after adjusting for covariates. Pedigree and genotype data were screened for possible errors using ASPEX software, version 2.2 [14], MAPMAKER/SIBS, version 2.1 [15], PedCheck, version 1.1 [16], and PREST, version 2.01 [17].

The heritability of serum measures was estimated separately in each race and jointly, using variance component modelling as implemented in SOLAR software, version 2.1.2 [18]. Covariates in the model for fasting glucose were age, sex, BMI, age ${ }^{2}$, and age $\times$ sex. Covariates in the model for fasting insulin were age, sex, BMI, age ${ }^{2}$, age $\times$ sex, sex $\times$ BMI, and sex $\times$ age $^{2}$. These were selected using a backward elimination approach allowing for re-entry of eliminated covariates at each step (significance level= 0.10 for backward and forward steps). For both analyses, covariates were selected among age, sex, and BMI, age ${ }^{2}$, age $\times$ sex, age $\times$ BMI, sex $\times$ BMI, sex $\times a^{2} e^{2}$, and BMI $\times$ age $^{2}$. Centred values were used to 
Table 1 Demographic characteristics of HyperGEN study population

Data listed as means \pm standard deviation $(n)$ for continuous measures and $\%(n)$ for dichotomous measures

${ }^{a}$ Defined as blood pressure $>140 / 90 \mathrm{mmHg}$ or use of antihypertensive medication

\begin{tabular}{|c|c|c|c|}
\hline Characteristic & African American & Caucasian & Race combined \\
\hline \multicolumn{4}{|l|}{ Sex } \\
\hline Female & $65.6(836)$ & $52.6(599)$ & $59.5(1,435)$ \\
\hline Male & $34.4(438)$ & $47.4(539)$ & $40.5(977)$ \\
\hline Age, years & $46.7 \pm 12.7(1,274)$ & $55.8 \pm 13.1(1,138)$ & $51.0 \pm 13.7(2,412)$ \\
\hline BMI, $\mathrm{kg} / \mathrm{m}^{2}$ & $31.8 \pm 7.6(1,274)$ & $29.5 \pm 6.1(1,138)$ & $30.7 \pm 7.0(2,412)$ \\
\hline Fasting serum glucose, $\mathrm{mmol} / \mathrm{l}$ & $5.32 \pm 1.14(1,247)$ & $5.42 \pm 1.46(1,109)$ & $5.37 \pm 1.30(2,356)$ \\
\hline Fasting serum insulin, mU/1 & $10.8 \pm 11.2(1,093)$ & $8.0 \pm 5.7(1,078)$ & $9.4 \pm 9.0(2,171)$ \\
\hline Hypertension $^{\mathrm{a}}$ & $70.2(894)$ & $73.6(838)$ & $71.8(1,732)$ \\
\hline
\end{tabular}

\section{Results}

Genotype data were available from 2,589 individuals in 805 recruited families who participated in the FBPP. Eight subjects were excluded due to fasting serum glucose concentrations above $6.99 \mathrm{mmol} / \mathrm{l}$ (six AA, two EA). After correcting family relationships based upon the genetic data, 1,030 distinct pedigrees (613 of whom were African American) were used in the analysis. After exclusion of all influential outliers, 2,412 of the genotyped individuals who were nondiabetic had measurements of fasting serum insulin and/or glucose concentrations. The mean age $( \pm \mathrm{SD})$ of these individuals was $51.0 \pm 3.7$ years, $59.5 \%(N=1,435)$ were women, $53 \%$ were AA $(N=1,279)$, and a majority were hypertensive $(71.7 \%)$ and had a mean BMI $( \pm \mathrm{SD})$ of $30.70 \pm 6.98 \mathrm{~kg} / \mathrm{m}^{2}$ (Table 1$)$. Participants had a mean fasting serum glucose concentration
Fig. 1 Genome scan plots for fasting serum insulin concentrations. Dotted line African Americans; solid line Caucasians
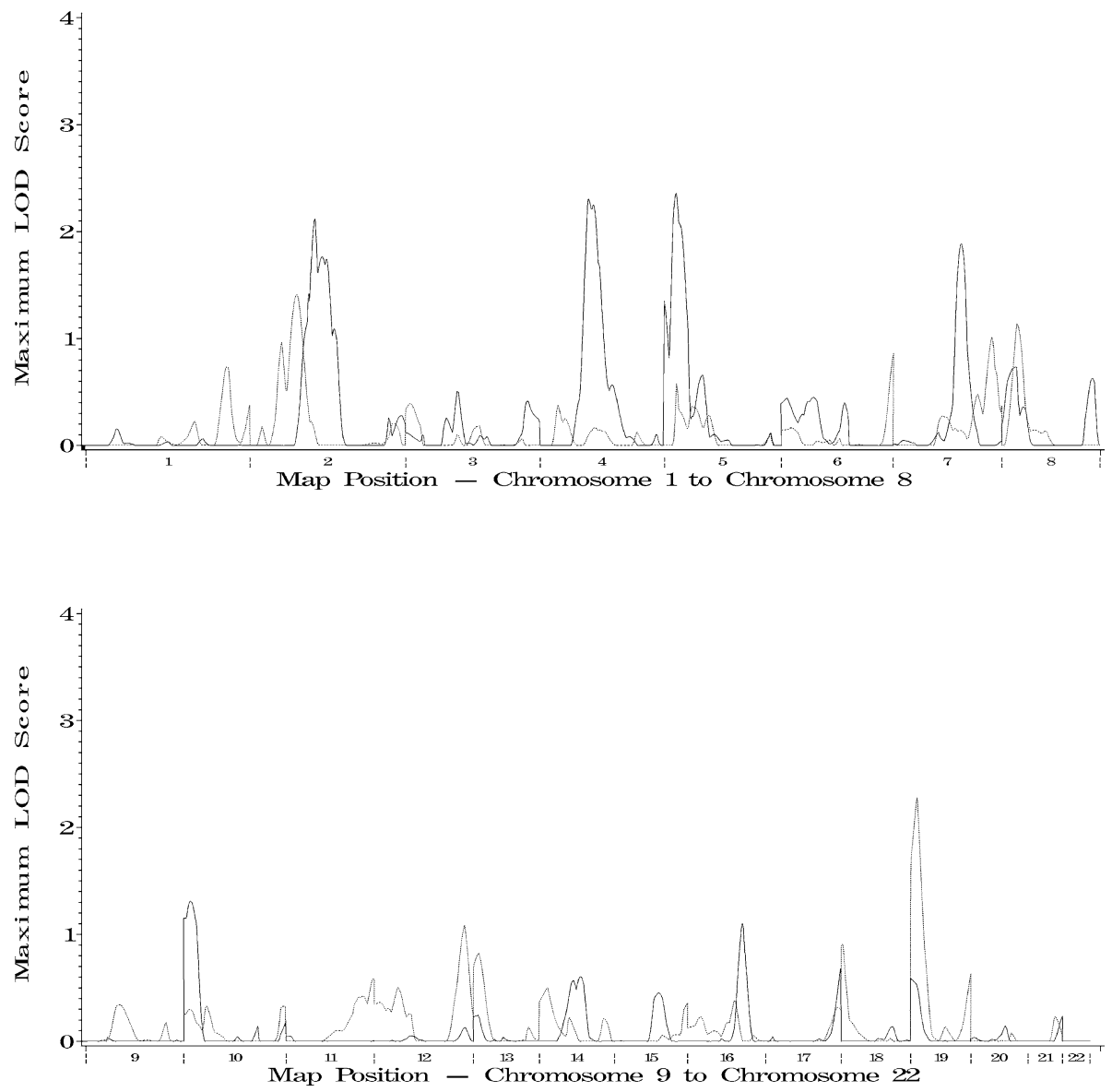


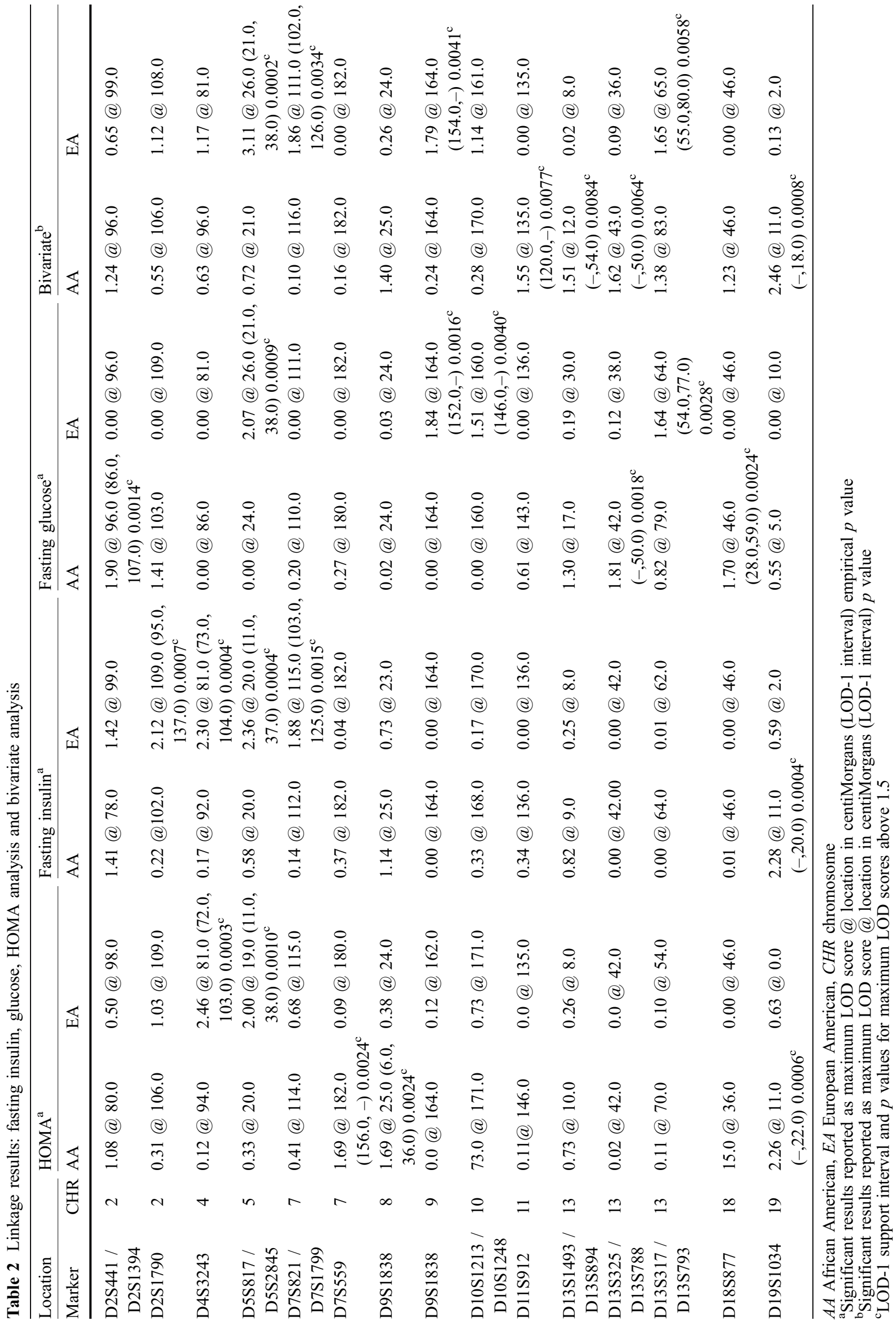


Fig. 2 Genome scan plots for HOMA. Dotted line African Americans; solid line Caucasians
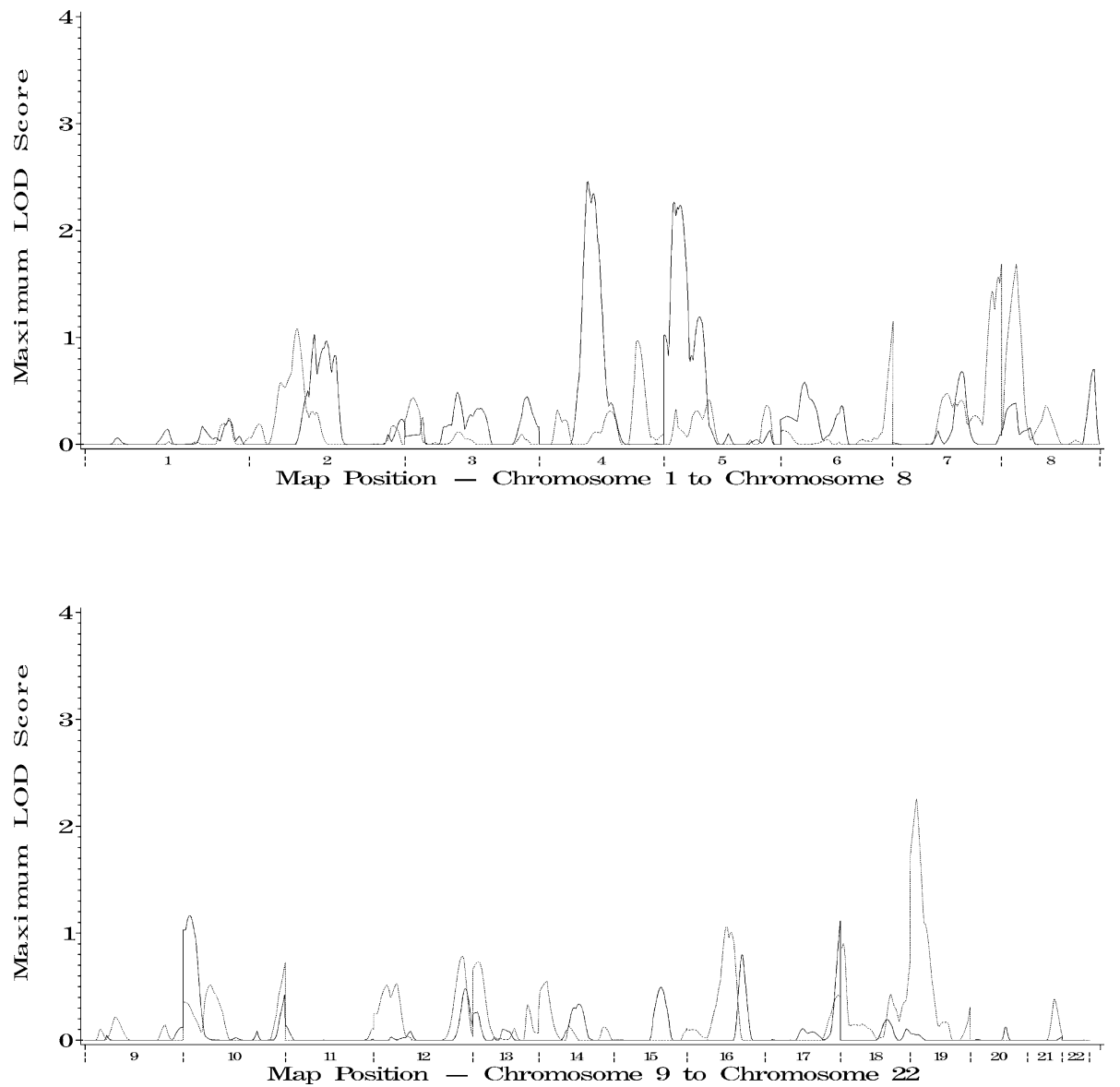

of $5.37 \pm 1.30 \mathrm{mmol} / \mathrm{l}$ and a mean fasting serum insulin concentration of $9.40 \pm 9.0 \mathrm{mU} / 1$. Among these 2,412 individuals, there were 1,329 sibling pairs (513 AA), 610 avuncular pairs (190 AA), 156 half-sibling pairs (144 AA), 185 first cousins (54 AA), and 2 EA monozygotic twins. The mean family size with insulin and/or glucose data was 2.34 members (AA 2.09 , EA 2.73).

The $h^{2}$ of serum insulin was $0.47 \pm 0.08$ in EAs and $0.28 \pm$ 0.08 in AAs ( $p<0.0001$ for both), after controlling for the significant main and interactive effects of age, sex and BMI. An additional $33 \%$ and $31 \%$ of the variance in EAs and AAs, respectively, was due to measured covariates. Figure 1 contains the univariate genome-wide scan results for fasting erum insulin concentration in EAs and AAs. A maximum LOD score of 2.36 was observed on chromosome 5 at 20.0 $\mathrm{cM}$ (marker D5S817/D5S2845, $p=0.0004)$, with lesser peaks of LOD 2.30 on chromosome 4 (81 cM, marker D4S3243) and 2.12 on chromosome $2(109 \mathrm{cM}$, marker D2S1790) in EAs, and 2.28 on chromosome 19 (11 cM, marker D19S1034) in AAs, $p<0.0007$ for all (Fig. 1). Table 2 contains the results of the genome scan for fasting serum insulin (as well as for HOMA, fasting serum glucose and the bivariate analysis), reporting maximum LOD scores of more than 1.5 , position, LOD-1 interval and $p$ value in AAs and EAs (see symbols and footnotes) and maximum LOD scores with position in all other scans in proximity to the significant results. The results of the HOMA genome scan are presented in Fig. 2 and Table 2. Similar regions of linkage were observed for fasting serum insulin concentrations on chromosomes 4 and 5 in EAs and on chromosome 19 in AAs.

The $h^{2}$ of serum glucose concentration was $0.51 \pm 0.08$ in EAs and $0.29 \pm 0.09$ in AAs ( $p \leq 0.0003$ for both), after controlling for the significant main and interactive effects of age, sex, and BMI. An additional $22 \%$ and $20 \%$ of the variance in EAs and AAs, respectively, was due to measured covariates. The univariate genome-wide scan results for fasting serum glucose are depicted in Fig. 3. A maximum LOD score of 2.07 was observed on chromosome 5 at $26.0 \mathrm{cM}$ (marker D5S817/D5S2845, $p=0.0009$ ) in EAs and a lesser peak was observed on chromosome 2: LOD 1.90 at $96.0 \mathrm{cM}$ (marker D2S441/D2S1394), $p<0.0014$ in AAs (Fig. 3; Table 2).

In AAs, the genetic correlation between fasting serum glucose and insulin was nonsignificant $(p=0.37)$, while the environmental correlation was $r_{\mathrm{E}}=0.46 \pm 0.07(p<0.0001)$. In EAs, the genetic correlation between fasting serum glucose and insulin was also nonsignificant $(p=0.86)$, while the environmental correlation was $r_{\mathrm{E}}=0.35 \pm 0.10(p=0.0007)$. These data suggest that the primary genetic determinants of fasting serum glucose concentration are different from those that contribute to the variation in fasting serum insulin concentration. A bivariate genome-wide scan for loci contributing to both fasting serum glucose and insulin concentrations in both races demonstrated eight regions with maximum LOD scores above 1.5 (four in AAs and four 
Fig. 3 Genome scan plots for fasting serum glucose concentrations. Dotted line African Americans; solid line Caucasians
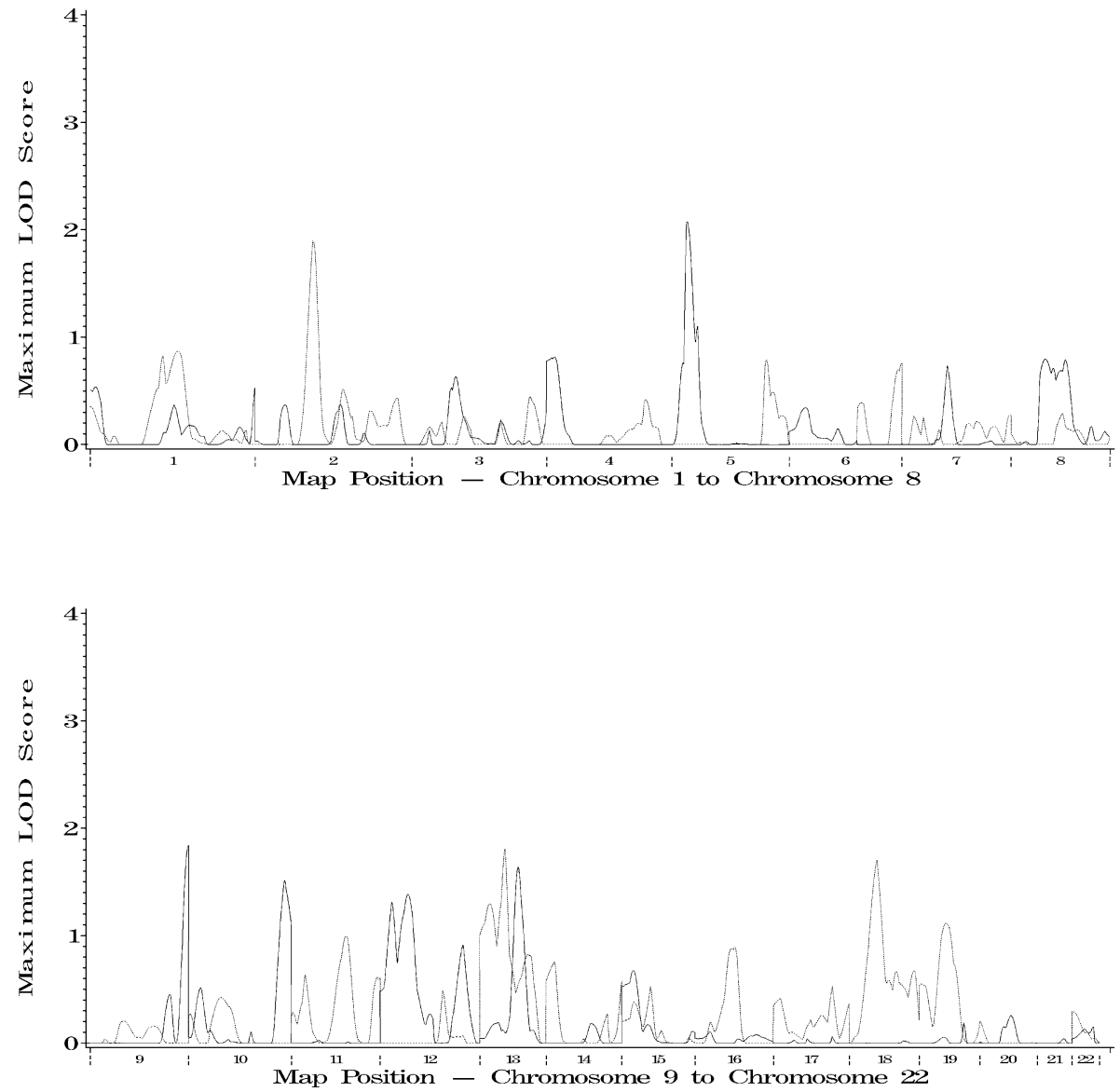

in EAs). These regions are depicted, separately by race, in Fig. 4 and Table 2.

\section{Discussion}

This report is the first to reveal that inherited factors appear to play important roles in the regulation of fasting serum insulin and glucose concentrations in hypertensive, nondiabetic AAs and Caucasians. The heritability of fasting serum insulin and glucose concentrations remained highly significant even after controlling for the effects of significant covariates. The marked heritability of fasting serum glucose and insulin concentrations appears consistent with other reports in Framingham [6, 7], Amish [8], and HERITAGE families [9]. Additionally, the genome scans in AAs and EAs provided suggestive evidence that genes regulating fasting serum insulin concentrations and insulin sensitivity (HOMA) were present on chromosomes 19, 7, 5, 4 and 2, and genes regulating fasting glucose concentration were present on chromosomes 2, 5, 9, 13 and 18. In general, the linkage peaks for fasting insulin, HOMA and fasting glucose differed by ethnic group (see Table 2). Race-combined analyses added little, as results were driven by a single ethnic group (data not shown). Although the bivariate genome scan demonstrated several regions with suggestive evidence for linkage, these results were probably driven by linkage to either fasting serum insulin or fasting serum glucose con- centrations alone, based on the low genetic correlation observed between these measures.

Several genome-wide scans have been performed in nondiabetic families evaluated for prediabetic phenotypes and in multiplex type 2 diabetes families. Regions of linkage in several reports overlap with those observed in this HyperGEN analysis. On chromosome 19, linkage was detected at $18 \mathrm{cM}$ for fasting insulin in Pima Indians (LOD 1.33) [23], and for type 2 diabetes and glucose intolerance in young-onset French families at $36 \mathrm{cM}$ (LOD 1.26) [24]. Linkage with fasting glucose, and combined fasting and non-fasting glucose, was detected on chromosome 5 at 0 $\mathrm{cM}$ in the Framingham Offspring Study (LOD 1.09) [6], and Framingham Heart Study (LOD 1.65) [25]. The HyperGEN fasting serum glucose scan loci on chromosome 13 are near reported loci for related phenotypes in 580 Finnish families from the FUSION Study [26], i.e., 2-h insulin (LOD 2.86 at $65 \mathrm{cM}$ ) and insulin secretion (insulin/ glucose) (LOD 1.37 at $62 \mathrm{cM}$ ), and loci for type 2 diabetes in AAs with earlier age at diagnosis $(p<0.006$ at $76 \mathrm{cM})$ [27] and Japanese families (LOD 0.94, $79 \mathrm{cM}$ ) [28]. Linkage for these phenotypes resides within, or near, the peaks where we found evidence for linkage to fasting insulin (chromosomes 19 and 5) and fasting glucose (5 and 13) in the univariate analyses. Therefore, the regions identified in the HyperGEN genome scan as influencing fasting serum insulin and glucose concentrations may reflect genes that also play major roles in susceptibility to diabetes mellitus 
Fig. 4 Genome scan plots for bivariate analysis of fasting serum glucose and insulin concentrations. Dotted line African Americans; solid line Caucasians
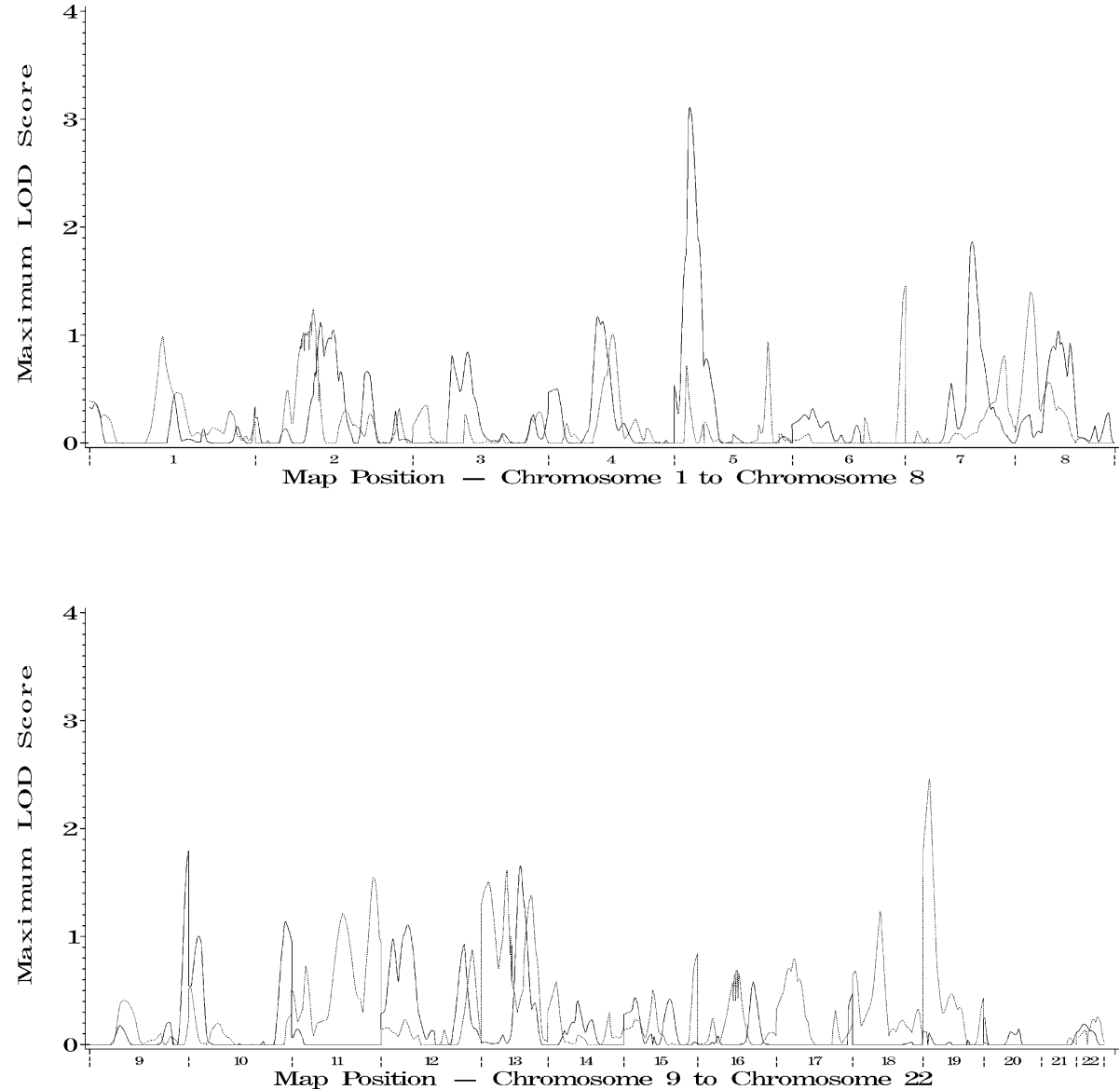

and/or related phenotypes. Our data are unique, however, in that they are from a biracial population enriched for the presence of essential hypertension.

Fasting serum glucose concentrations clearly fluctuate in individuals with insulin resistance and in those with diabetes mellitus. In addition, little is known about the natural history of insulin resistance among treated and untreated hypertensive subjects. These difficulties are encountered in all cross-sectional studies. The overlapping regions of linkage observed for the diabetes-related phenotypes in Pima [23] and Finnish [26] families, and the Framingham Offspring [6] and Heart Studies [25], support the existence of genes affecting fasting serum insulin concentrations on chromosomes 19 and 5 and fasting serum glucose on chromosome 13 .

In conclusion, this report analysed the heritability of fasting serum insulin and glucose concentrations in nondiabetic members of multiplex hypertensive families. Elevated serum insulin concentrations and fasting blood sugars (insulin resistance) are well recognised risk factors for the development of heart attack and stroke. The heritabilities of fasting serum insulin and glucose concentrations were significant after controlling for the main and interactive effects of age, sex, and BMI. Additionally, suggestive evidence for genetic linkage to fasting serum insulin concentrations and insulin sensitivity (HOMA) were detected on chromosomes $19,5,4$, and 2 ; and suggestive evidence for linkage to fasting serum glucose concentrations was detected on chromosomes 2 , $5,9,13$, and 18 . These results suggest that the genes regulating susceptibility to insulin resistance, hyperglycaemia and diabetes-related phenotypes may reside in these regions and play an important role in the observed familial aggregation of cardiovascular disease. It is important that additional large, family-based analyses in hypertensive cohorts attempt to reproduce these results and identify the causative genes.

Acknowledgements HyperGEN participating institutions and principal staff: S.C. Hunt, R.R. Williams (deceased), H. Coon, P.N. Hopkins, J. Hood, L. Wu, J. Skuppin (Network Center/University of Utah Field Center); A. Oberman, C.E. Lewis, M.T. Weaver, P. Johnson, S. Walker, C. Oden (University of Alabama at Birmingham Field Center); R.C. Ellison, R.H. Myers, Y. Zhang, L. Djoussé, J.B. Wilk, G.L. Splansky (Boston University/Framingham Field Center); D. Arnett, A.R. Folsom, M. Miller, J. Pankow, G. Feitl, B. Lux (University of Minnesota Field Center); G. Heiss, B.I. Freedman, K. North, K. Rose, A. Haire (University of North Carolina Field Center); D.C. Rao, M.A. Province, I.B. Borecki, A. Adelman, D. Morgan, K. Schwander, D. Lehner, A. Kraja, S. Mandel (Data Coordinating Center, Washington University); J.H. Eckfeldt, C. Leiendecker-Foster, R.C. McGlennen, G. Rynders, M.Y. Tsai, J. Bucksa (Central Biochemistry Lab, University of Minnesota); M. Leppert, S.C. Hunt, J.M. Lalouel, R. Weiss (Molecular Genetics Laboratory, University of Utah); S.E. Old, M. Higgins (retired), C. Jaquish, M. Lundberg, M. Gerschenson (National Heart, Lung, and Blood Institute).

This hypertension network is funded by cooperative agreements (U10) with NHLBI: HL54471, HL54472, HL54473, HL54495, HL54496, HL54497, HL54509, HL54515. 


\section{References}

1. Haffner SM, Valdez RA, Hazuda HP, Mitchell BD, Morales PA, Stern MP (1992) Prospective analysis of the insulin-resistance syndrome (syndrome X). Diabetes 41:715-722

2. Laaksonen DE, Lakka HM, Niskanen LK, Kaplan GA, Salonen JT, Lakka TA (2002) Metabolic syndrome and development of diabetes mellitus: application and validation of recently suggested definitions of the metabolic syndrome in a prospective cohort study. Am J Epidemiol 156:1070-1077

3. Snieder H, Boomsma DI, van Doornen LJ, Neale MC (1999) Bivariate genetic analysis of fasting insulin and glucose levels. Genet Epidemiol 16:426-446

4. Ferrannini E, Haffner SM, Mitchell BD, Stern MP (1991) Hyperinsulinaemia: the key feature of a cardiovascular and metabolic syndrome. Diabetologia 34:416-422

5. Haffner SM, D’Agostino R Jr, Mykkanen L et al (1999) Insulin sensitivity in subjects with type 2 diabetes. Relationship to cardiovascular risk factors: the Insulin Resistance Atherosclerosis Study. Diabetes Care 22:562-568

6. Meigs JB, Panhuysen CI, Myers RH, Wilson PW, Cupples LA (2002) A genome-wide scan for loci linked to plasma levels of glucose and $\mathrm{HbA}(1 \mathrm{c})$ in a community-based sample of Caucasian pedigrees: the Framingham Offspring Study. Diabetes 51:833-840

7. Panhuysen CI, Cupples LA, Wilson PW, Herbert AG, Myers RH, Meigs JB (2003) A genome scan for loci linked to quantitative insulin traits in persons without diabetes: the Framingham Offspring Study. Diabetologia 46:579-587

8. Hsueh WC, St Jean PL, Mitchell BD et al (2003) Genome-wide and fine-mapping linkage studies of type 2 diabetes and glucose traits in the Old Order Amish: evidence for a new diabetes locus on chromosome $14 \mathrm{q} 11$ and confirmation of a locus on chromosome 1q21-q24. Diabetes 52:550-557

9. Hong Y, Weisnagel SJ, Rice T et al (2001) Familial resemblance for glucose and insulin metabolism indices derived from an intravenous glucose tolerance test in Blacks and Whites of the HERITAGE Family Study. Clin Genet 60:22-30

10. Edelstein SL, Knowler WC, Bain RP et al (1997) Predictors of progression from impaired glucose tolerance to NIDDM: an analysis of six prospective studies. Diabetes 46:701-710

11. Williams RR, Rao DC, Ellison RC et al (2000) NHLBI family blood pressure program: methodology and recruitment in the HyperGEN network. Hypertension genetic epidemiology network. Ann Epidemiol 10:389-400

12. Allauzen S, Mani JC, Granier C, Pau B, Bouanani M (1995) Epitope mapping and binding analysis of insulin-specific monoclonal antibodies using a biosensor approach. J Immunol Methods 183:27-32

13. Pesce AJ, Kaplan LA (eds) (1987) Methods in clinical chemistry. C.V Mosby, St. Louis
14. Hinds DA, Risch N (1996) The ASPEX package: affected sibpair exclusion mapping. Version 1.94. http://aspex.sourceforge. net/usage.html (accessed 18/09/2003)

15. Kruglyak L, Lander ES (1995) High-resolution genetic mapping of complex traits. Am J Hum Genet 56:1212-1223

16. O'Connell JR, Weeks DE (1998) PedCheck: a program for identification of genotype incompatibilities in linkage analysis. Am J Hum Genet 63:259-266

17. McPeek MS, Sun L (2000) Statistical tests for detection of misspecified relationships by use of genome-screen data. Am J Hum Genet 66:1076-1094

18. Almasy L, Blangero J (1998) Multipoint quantitative-trait linkage analysis in general pedigrees. Am J Hum Genet 62:11981211

19. Heath SC (1997) Markov chain Monte Carlo segregation and linkage analysis for oligogenic models. Am J Hum Genet 61: $748-760$

20. Goldgar DE (1990) Multipoint analysis of human quantitative genetic variation. Am J Hum Genet 47:957-967

21. Amos CI (1994) Robust variance-components approach for assessing genetic linkage in pedigrees. Am J Hum Genet 54: $535-543$

22. Almasy L, Dyer TD, Blangero J (1997) Bivariate quantitative trait linkage analysis: pleiotropy versus co-incident linkages. Genet Epidemiol 14:953-958

23. Pratley RE, Thompson DB, Prochazka M et al (1998) An autosomal genomic scan for loci linked to prediabetic phenotypes in Pima Indians. J Clin Invest 101:1757-1764

24. Vionnet N, Hani El H, Dupont S et al (2000) Genomewide search for type 2 diabetes-susceptibility genes in French whites: evidence for a novel susceptibility locus for early-onset diabetes on chromosome 3q27-qter and independent replication of a type 2-diabetes locus on chromosome 1q21-q24. Am J Hum Genet 67:1470-1480

25. McQueen MB, Bertram L, Rimm EB, Blacker D, Santangelo SL (2003) A QTL genome scan of the metabolic syndrome and its component traits. BMC Genet 4(Suppl 1):S96

26. Watanabe RM, Ghosh S, Langefeld CD et al (2000) The Finland-United States investigation of non-insulin-dependent diabetes mellitus genetics (FUSION) study. II. An autosomal genome scan for diabetes-related quantitative-trait loci. Am J Hum Genet 67:1186-1200

27. Sale MM, Freedman BI, Langefeld CD et al (2004) A genomewide scan for type 2 diabetes in African-American families reveals evidence for a locus on chromosome 6q. Diabetes 53:830-837

28. Iwasaki N, Cox NJ, Wang YQ et al (2003) Mapping genes influencing type 2 diabetes risk and BMI in Japanese subjects. Diabetes 52:209-213 